\title{
FINANCIAL EDUCATION FOR LOW-INCOME WOMEN: A PARALLEL TO SOCIAL AND COLLABORATIVE ECONOMY
}

Thiago Godoy Nascimento thiagognasc@gmail.com Getúlio Vargas Foundation - FGV, São Paulo, São Paulo, Brazil.

\begin{abstract}
The understanding of the daily financial habits of low-income women, specifically the beneficiaries of the Bolsa Familia Program, is the starting point of a field study conducted by the Brazilian Financial Education Association (AEF-Brasil), organization that operates the National Strategy Financial Education, federal state policy. The understanding of such habits led to the development of educational social technology for this vulnerable public, aiming to improve their behavior in relation to money, especially the planning and the pursuit of the realization of dreams. It is related to understanding how such Technology would impact the lives of these women and their families, as well as on the engagement and reflection on the role of the Social and Collaborative Economy in the new economic arrangements, especially among populations that are on the margins of the consumer society.
\end{abstract}

Keywords: Financial Education; Collaborative; Social; Technology. 


\section{INTRODUCTION}

This article aims to establish a parallel between Public-Private Policies and their contribution to the Social Economy and Solidarity as well as to the Creative Economy. It also highlights the importance of Private Social Investment and its alignment with Public Policies, promoting greater impact and scalability. In order to establish this parallel, this article will analyze a project developed by the National Strategy for Financial Education (ENEF), a multisectoral mobilization around the promotion of financial education actions in Brazil, instituted as a permanent State policy and created through Federal Decree 7.397 / 2010.

The objective of this project was to develop skills and abilities so that one of the country's lowest income segments - women beneficiaries of the Bolsa Família Program $(\mathrm{PBF})^{1}$ can efficiently manage their family budget, in order to achieve objectives, promoting financial autonomy for behavior and attitude, involving individual decision-making and impacting the family environment. The project was developed and tested between 2014 and 2017 and was sponsored by the Inter-American Development Bank and the Citibank Foundation, in addition to counting on the partnership through an agreement with the Ministry of Social Development, culminating in the development (with the beneficiary public) of Social Technologies (ST) in the subject of financial education that could cause the behavior change of each beneficiary of the PBF. After an impact assessment, a $39 \%$ increase in the proportion of PBF beneficiaries who had a reserve of money (in a financial institution or in the home) and a 53\% increase in the amount saved were identified, with significant gains in terms of knowledge on financial planning.

Creative Economy is the set of initiatives based on intellectual and cultural capital and creativity that generates economic value. The creative industry stimulates income generation, creates jobs and produces revenues from exports, while promoting cultural diversity and human development. The Creative Economy encompasses the cycles of creation, production and distribution of goods and services that use creativity, culture and intellectual capital as primary inputs. Howkins (2001) developed the concept to describe economic systems where value is based on novel imaginative qualities rather than the traditional resources of land, labor and capital. Compared to creative industries, which are limited

1 Bolsa Família is a Cash Transfer program that contributes to the fight against poverty and inequality in Brazil. It was created in October 2003 and has three main axes of income complement, access to rights and articulation with other actions. The Bolsa Família Program is provided for in Law - Federal Law No. 10,836, of January 9, 2004 - and is regulated by Decree No. 5,209, of September 17, 2004, and other regulations. to specific sectors, the term is used to describe creativity throughout a whole economy.

The following chapters will detail the main aspects of the conception of the National Strategy for Financial Education, the project for women in the BSF, and the results of the impact and the importance of mobilizing the various sectors of the economy for the success of this initiative.

\section{THE NATIONAL STRATEGY FOR FINANCIAL EDUCATION - STATE POLICY WITH PRIVATE SOCIAL INVESTMENT}

The National Strategy for Financial Education (ENEF) is a multisectoral mobilization around the promotion of financial education actions in Brazil. The strategy was instituted as a permanent State policy, and its main characteristics are the guarantee of gratuity of the initiatives that it develops or supports and its commercial impartiality. The objective of ENEF, created through Federal Decree 7,397 / 2010, is to contribute to the strengthening of citizenship by providing and supporting actions that help the population to make more autonomous and conscious financial decisions. The strategy was created through the articulation of seven government bodies and entities and four civil society organizations, which together form the National Committee on Financial Education (CONEF).

ENEF programs are guided by a Master Plan. Their Deliberation and Annexes are documents that consolidate the performance of the National Strategy of Financial Education. ENEF's actions are comprised of cross-sectoral and sectoral programs, coordinated centrally, but implemented in a decentralized manner. The governance structure of ENEF includes public and private entities interested in promoting financial education in Brazil. The format preserves the independence of the supervisory bodies of the financial system to develop their own educational actions.

As a national policy, ENEF should contemplate the strategic governance spheres (1), with the CONEF being responsible for the direction, supervision and promotion of ENEF. It consists of seven government bodies and entities and four civil society organizations. The Central Bank of Brazil, the Securities Commission, the National Supplementary Pension Authority, the Private Insurance Superintendency, the Ministry of Justice and Citizenship, the Ministry of Education and the Ministry of Finance are members of the government. The representatives of the Committee from civil society are Anbima (Brazilian Financial and Capital Markets Association), B3 (B3 formerly BM\&FBOVESPA, the Brazilian Stock Exchange), CNseg (National Insurance Companies Confederation) and Febraban (Brazilian Federation of Banks). 
As a consultative body, a Pedagogical Support Group (GAP) was established for providing advice to CONEF on pedagogical aspects related to financial and social security education. It is composed of representatives of each of the organs and entities of CONEF plus 5 Federal Education Institutions (one per Brazilian region), the National Education Council, the Council of Secretaries of Education and the Union of Municipal Education Officers.

In order to promote the necessary technical support to the National Strategy for Financial Education, a Permanent Committee was formed and it provides a representative and an alternate member of each entity or body that is a member of CONEF. There is also an Executive Secretariat that provides suppliers the administrative support and the necessary means to achieve the objectives of CONEF, and it is exercised by the Central Bank of Brazil.

In order to carry out the coordination and execution of the transversal actions of ENEF, in 2011 the AEF-Brasil (Brazilian Financial Education Association) was created, an Organization of Civil Society of Public Interest (OSCIP) that has on its Board ANBIMA, B3, CNSEG and FEBRABAN with the objectives of coordinating and executing the transversal actions of ENEF and promoting financial education in Brazil through the development of social and educational technologies related to the subject.

In addition to all the above configurations, the Brazilian National Strategy for Financial Education mobilizes resources with the private sector for the development and execution of its transversal projects. The participation and investment of companies and organizations that understand as essential and strategic the development of financial education in the country ensures the scalability and sustainability of the initiative, since it diversifies the sources of investment and promotes the articulation of a robust and multisectoral network. The National Strategy for Financial Education in Brazil has a modern configuration and has been admired by other countries.

\section{FINANCIAL EDUCATION PROJECT FOR WOMEN BENEFICIARIES OF THE BOLSA FAMÍLIA PROGRAM (PBF) - SOCIAL AND COLLABORATIVE ECONOMY}

\subsection{Introduction}

The project was conceived and developed to serve one of the most vulnerable low income segments of Brazil, women beneficiaries of the PBF. Due to its high vulnerability, low level of education and limited resources, the financial benefit granted must be used in order to effectively improve the living conditions of this population, and therefore, Financial
Education is an essential element in the empowerment process of this public. The absence of the conscious financial decision-making process of this public leads to poor budget planning, low levels of savings and over-indebtedness.

There are 13.4 million families that benefit, $90 \%$ of which are women. Single mothers and heads of households accounted for $42 \%$ of the beneficiaries. Of the total number of enrolled beneficiaries, only $30 \%$ have complete primary education and have great difficulty in entering the labor market, with very variable income sources.

This project was built on the basis of experimental and impact assessment methodology to develop solutions that respond to the unique realities of the target population through methodologies that meet their needs and can be easily incorporated into daily life.

The main objective of this project is to develop skills and abilities so that women can efficiently manage the family budget in order to achieve objectives, promoting financial autonomy through a change in behavior and attitude, involving individual decision making and impacting the environment family.

It is considered social technology any product, method, process or technique, created to solve some type of social problem and that meets the requirements of simplicity, low cost, easy applicability (and replicability) and proven social impact. Other terms such as "social technique", "social pedagogy", or "administrative technique" are used by other authors as well, and the aim on the social is common to all the terms, as it should be dealt with and be acted upon and as it describes the usage of sociological knowledges to solve practical problems. The knowledge of social sciences is used and provides applied expertise for specific decisions, actions and purposes, applying methods and theories to obtain a scientific based analysis for a purpose, which is, then, used for political decisions. Technique refers to the application of specific evidence in everyday life, in contrast to technology described as a system of evidence (Büschges, 2002).

There was great challenge in incorporating the Financial Educational Social Technology into women's lives, especially because this adult, heterogeneous and non-institutionalized population is harder to be found. We also must consider that the adult learning process is different from that of young people and that there are regional differences as well. The fact that the beneficiaries do not attend an institution and are routinely focused on solving family and/or professional emergencies is a challenge, making it difficult to bring these women together and create a systematic educational process.

Given the complexity, it was decided to adopt a combination of the following areas of knowledge in the project: 
Service design: a transdisciplinary approach that integrates tools and methods with the aim of developing services and experiences centered on human beings.

Behavioral sciences: it aims to observe and understand human behavior and the decision-making processes scientifically. It encompasses psychology, neuroscience, and economics. With regard to financial education, economic psychology has foundations that ground changes in habits and principles that generate behavioral changes in relation to new financial decision making.

Public administration: it aims to understand and identify ways of intervening in the process of formulating public policies and state organization.

The structure of the project is based on the methodological approach of design thinking, as the following principle: focus on human beings through the understanding of the people you wish to provide benefit and their context;

The project was structured by cycles, as detailed below:

- Cycle 1 - Understanding: immersion into the context of beneficiary women and the research and documents of the PBF, in order to understand the operation of the program and patterns of the financial behavior of beneficiaries. There were four months of field research involving 80 women in 15 municipalities in the N, NE and SE regions, including urban and rural areas, as well as riverside communities, resulting in four different "personas" that inspired the production of social technologies.

- Cycle 2 - Definition and Experimentation: based on the findings of Cycle 1 , ideas of ways to contribute to the reduction and prevention of over-indebtedness were generated. Based on the feasibility criteria of application and dissemination, ideas that became prototypes - that is, initial samples that can become a social technology were chosen, bringing a demonstration of content, language, and format. During this Cycle, there are prototyping 3 rounds and in each prototype was refined, excluded or incorporated, until the final version arrived. 1,500 women participated, in order to provide evidence on the elements that best fit and should be included in a social technology, to be disseminated later on a national scale.

- Cycle 3 - Systematization: at the end of the test rounds, the resulting social technology has been systematized and is available in formats that facilitate dissemination and adoption by governmental organizations or NGOs. All materials are made available on a website that will keep, free of charge and publicly available, social technologies as well as the ways of using them.

- Cycles 4 and 5 - Application on a larger scale, evaluation, and revision of social technology: in order to reapply and incorporate social technology into existing programs and policies, a pilot study involves 1500 women in a treatment group and 1500 women in a control group. The technology was applied by local agents, followed by treatment and control groups, who underwent the first evaluation that collected data on the level of knowledge of topics related to financial education and on a specific financial behavior - indebtedness. After 6 months, a new evaluation was conducted, seeking differences between the Control and Treatment groups.

A set of 20 Social Technologies was developed based on the experimental experience methodology, with the participation of beneficiaries in different regions of the country, seeking a better understanding of the reality of the family and the environment.

The low income urban communities served by the project have the offer of services as their main economic activity. The project fosters, in addition to the organization and planning of the personal finances of the participants, entrepreneurship and income generation. In all municipalities where the project was applied, the impact was quite significant: in the beneficiary itself, which started to manage its meager resources better; in the family environment, which now has a better distribution of resources; in the community, because once women become empowered, they acquire greater financial autonomy and, finally, enabling a greater economic and social inclusion of this vulnerable layer of society.

\subsection{Problematic}

The main problem that the project intends to change is the cycle of poverty generated by the lack of opportunities and information in regions of high vulnerability.

The World Bank predicts an increase in Brazil's poverty situation based on distinct variations of macroeconomic indices. With a positive outlook for 2017, the number of moderately poor people will reach 19.8 million $(9.8 \%$ of the population), including those who will be in extreme poverty - about 8.5 million people (4.2\%). This is a situation that can be mitigated by means of financial education.

The BFP reaches three dimensions: a) reducing poverty by transferring direct income to families; b) contributing to the disruption of the poverty cycle through conditionality; c) 
in addition to developing the potential of families through complementary programs, such as the one proposed in this paper.

Another relevant issue of the project is to provide financial autonomy and empowerment for women. The National Survey by Household Sample (PNAD) of 2014 showed that the country has 6.3 million more women than men. But even in the face of this situation, the female population still faces daily diverse issues related to gender inequality and violence against women.

Poverty and social exclusion affect women and men differently according to sex because women are burdened with unpaid work, such as domestic chores and childcare; thus, this population should be provided with the chance of not maintaining dependency relationships with men, since they are often based on financial issues.

\subsection{International Agenda}

It is important to emphasize that the solution of this problem is of interest to social and governmental organizations and institutions around the world.

During the United Nations Summit on Sustainable Development in September 2015, the world agenda was launched with the 17 Sustainable Development Objectives (ODS) previously mentioned in this document. The Brazilian government has committed itself to the UN so that the first of them - Eradication of Poverty - is a priority of the country's agenda. In addition, the Ministry of Social Development and Fight against Hunger (MDS) is directly linked to the project from its conception to its implementation and dissemination.

Following the 17 ODS, international multilateral investment fund bodies, such as the World Bank and Inter-American Foundation, are also directly linked to the project's issues. The sponsors of the Pilot Project, the Inter-American Development Bank (IDB) and the Citi Foundation are also linked to the issue.

\subsection{Participation of beneficiaries in the construction of the methodology}

The participation of the beneficiaries occurred from the preparation of the materials to the application of the pilot project. In-depth interviews, round of discussion, participant observation, and in-depth immersion were carried out.

Those involved in this process were, in addition to the beneficiaries of the project, civil society organizations, public organizations, and the beneficiaries' families. At this stage it was possible to identify people that define in a very coherent way the different regions and habits in Brazil, in order to create profiles of each beneficiary. They were:

a) The dreamer: he has a low responsibility for the use of money because of the impulse to consumption;

b) The visionary: he generates equity and reserves and manages risks and investments;

c) The survivor: he tries to optimize the limited resources; and

d) The warrior: he focuses on short-term choices.

The in-depth study was essential for the development of social technologies that attend to each one of these people and that help in the understanding and practice of financial education in their daily life.

The following methodologies were used:

a) Social innovation: an approach used for complex problems by organizations that deal with social issues, having as principles the focus on human beings, collaboration between several actors and experimentation of social technologies that are the result of the intersection of what is desirable for the public in terms of people, resources (financial, technological), and political conditions.

b) Behavior Design: used not only to develop a social technology, but also to understand how it makes sense to users and how it is embodied by them in their day-to-day. To ensure adherence, social technology was developed based on motivation, accessibility (simplicity) and call to action.

c) Theory U: creates a path that helps teams access deeper levels of intelligence in order to capture the emerging future and realize it, generating disruptive innovations and collective transformations. This deepening path involves: suspending judgments; opening oneself to the deep listening of oneself and the other; experiencing reality from the point of view of the various actors; connecting with the most essential issues of a given challenge; witnessing the future in which one wants to be born; and from this, prototyping and crystallizing into responses that can be incorporated by institutions or that can become new structures.

d) Service design: it has an interdisciplinary approach that integrates a series of tools and methods with the aim of developing human-centered services or 
experiences that contribute to its well-being or improve its life in some way.

\subsection{Empowerment and Scalability}

The organization's capacity building training promotes the technical improvement of the individuals who work there with the necessary knowledge to carry out their work with greater competence. The capacity building of these community-based organizations is a conceptual approach to social and behavioral change and enables them to achieve measurable and sustainable results.

As scalability, a strategy is being worked on the building of a model of empowerment of social organizations working with low-income women and it is essential for the replicability and sustainability of the project.

Institutional capacity-building is an investment in the effectiveness and future sustainability of a non-profit organization. When capacity building and building work is successful, it strengthens a non-profit organization's ability to fulfill its mission over time, thus increasing the ability to have a positive impact on lives and communities.

The project has a high potential for reapplication since it focuses on the training processed by trainers, allowing the trained NGO agents to replicate the project among other NGOs and the NGOs in the region where they operate. This will be stimulated, monitored and measured by the executing team of this project.

\subsection{Evaluation and Impact of the Project - Education as an axis for the promotion of changes in habits and behaviors}

The chosen methodology was the experimental evaluation of social impact, recognized as the best way to identify the true effect of a program; therefore, it is the most recommended for programs whose objective is to become public and large-scale policies so that there is a greater confidence that the volume of resources invested will lead to the desired social return.

The evaluation of each modality of the program was carried out independently. Each one was composed of an intervention group (people drawn) and a control group (drawn for not participating), totaling 1,151 retirees and 2,002 beneficiaries of the PBF. About $60 \%$ of each group was drawn to participate in the workshops and the impact of the program was verified from the difference between the evolution of the intervention group and the control group regarding two questionnaires applied along with the registrations and about four months after the intervention workshops.
There is great distance between what women consider important and their daily behavior. They recognize the importance of saving money for contingencies; however, daily emergencies consume them and the formation of reserves does not occur.

The great distance between knowledge and behavior varies with the situation of life. Those who can recognize and verbalize their dreams are more motivated to manage and plan their resources, compared to those who believe that their life has no future. Depending on how much women move and seek, it will influence their relationship with money.

The more inert someone is, the more difficult it is to be empowered to make conscious and responsible financial decisions, given that the lack of education and information arises in difficulties in terms of organizing a life plan. Because these women have immediate issues to be solved and low schooling, it is important to approach financial education in a playful way, by means of concrete situations. For translating knowledge into action, it is necessary to offer intuitive simple-to-use tools that can be easily applied on a daily basis. The greater the involvement of families in financial goals, the easier it becomes to control resources and expenditures.

Although many have savings accounts, most do not consider themselves users of financial services and have difficulty understanding concepts, procedures and rights. One of the main points for family budget management is to support women beneficiaries of the BFP in the creation of reserves. This would prevent them from relying on more expensive ways to get money. In addition, a reserve helps women to take focus on the short term and on planning more.

The proportion of those who managed to fund an emergency in the three reference months among those attending the workshops has increased $75 \%$ and this percentage allowed funding an emergency with their own resources in the reference period.

The proportion of BBF that had a reserve of money (in a financial institution or at home) has increased by $39 \%$ among the participants. The amount of money saved (in financial institution or in the house) has increased by $53 \%$.

There was gain in terms of financial planning knowledge. The index composed of the correctness rate in questions of financial planning knowledge, according to the financial planning topics addressed by the program, increased by $73 \%$ among those who attended the workshops, in comparison to the non-attending BBFs. 


\section{CONCLUSIONS}

In the perspective of the Creative Economy, creativity and innovation are used as a raw material. The creation process is as important as the product end, that is, a production chain based on knowledge and able to produce wealth, generate jobs and distribute income. It is the entire business environment that exists around the creative industry, based on creative goods and services.

In the project presented, the process of developing a financial education technology was built as an ethnographic study, looking for understanding these public behaviors and thus prototyping a methodology tailored for them that is able to effectively change their behavior positively. The materials developed and tested had the objective of leveraging their financial literacy looking for their life perspective.

As for the findings revealed by this study, there is great distance between what women consider important and their daily behavior regarding finances. They recognize the importance of saving money for contingencies, but daily emergencies consume them and the formation of reserves does not occur.

Distance between knowledge and behavior varies with the situation of life. Those who can recognize and verbalize their dreams are more motivated to manage and plan their resources, compared to those who believe that their life has no future. How much women move and seek, influences their relationship with money.

The more inert, the more difficult it is to empower to make conscious and responsible financial decisions, given that the lack of education and information arises in difficulties of organizing a life plan.
Because these women have immediate issues to be resolved and have low levels of schooling, it is important to approach financial education in a playful way, with concrete situations. For translating knowledge into action, it is necessary to offer intuitive, simple-to-use tools that can be easily applied day-to-day.

The greater the involvement of families in financial goals, the easier it becomes to control resources and expenditures. Although many have savings accounts, most do not consider themselves users of financial services and have difficulty understanding concepts, procedures and rights.

One of the main points for family budget management is to support women in the PBF to create reserves. This would prevent them from relying on more expensive ways to get money. In addition, a reserve helps women to focus on the short term and on planning more.

Therefore, the social technology, which is characterized by a "learning-by-doing" process, can succeed and be efficient in building adequate tools in order to make this public-private partnership become more efficient and improve the living conditions of the beneficiaries of the program.

\section{REFERENCES}

Büschges, G. (2002), "Soziotechnik", in: Endruweit, G.; Trommsdorff, G (Ed.), Wörterbuch der Soziologie 2. völlig neubearbeitete und erweiterte Auflage, Lucius \& Lucius, Stuttgart, DE, pp. 560-1.

Comitê Nacional de Educação Financeira - CONEF (2010), Legislação, available from: http://www.vidaedinheiro.gov.br/ legislacao-2/ (accessed 2018 Aug 01).

Howkins, J. (2001), The Creative Economy: How People Make Money from Ideas, Allen Lane, Michigan.

Received: 12 Jan 2017

Approved: 25 Jul 2018

DOI: 10.14488/BJOPM.2018.v15.n3.a10

How to cite: Nascimento, T. G. (2018), "Financial Education for low-income women: a parallel to Social and Collaborative Economy", Brazilian Journal of Operations \& Production Management, Vol. 15, No. 3, pp. 432-438, available from: https://bjopm.emnuvens.com.br/bjopm/article/view/438 (access year month day). 